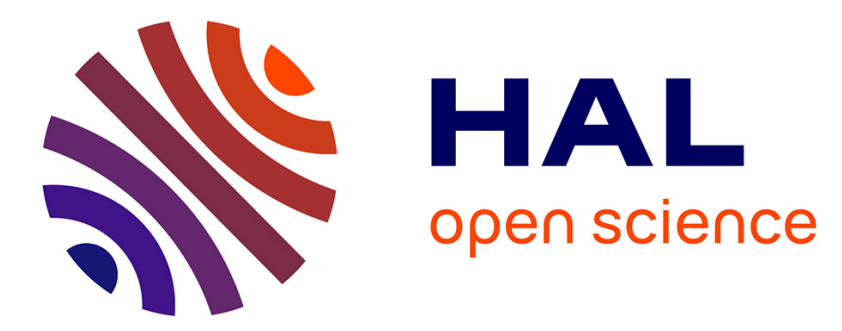

\title{
Influence of Carbon Nanotube-Polymeric Compatibilizer Masterbatches on Morphological, Thermal, Mechanical, and Tribological Properties of Polyethylene
}

\author{
Maija Pöllänen, Sami Pirinen, Mika Suvanto, Tuula T. Pakkanen
}

\section{- To cite this version:}

Maija Pöllänen, Sami Pirinen, Mika Suvanto, Tuula T. Pakkanen. Influence of Carbon NanotubePolymeric Compatibilizer Masterbatches on Morphological, Thermal, Mechanical, and Tribological Properties of Polyethylene. Composites Science and Technology, 2011, 71 (10), pp.1353. 10.1016/j.compscitech.2011.05.009 . hal-00768853

\section{HAL Id: hal-00768853 https://hal.science/hal-00768853}

Submitted on 26 Dec 2012

HAL is a multi-disciplinary open access archive for the deposit and dissemination of scientific research documents, whether they are published or not. The documents may come from teaching and research institutions in France or abroad, or from public or private research centers.
L'archive ouverte pluridisciplinaire HAL, est destinée au dépôt et à la diffusion de documents scientifiques de niveau recherche, publiés ou non, émanant des établissements d'enseignement et de recherche français ou étrangers, des laboratoires publics ou privés. 


\section{Accepted Manuscript}

Influence of Carbon Nanotube-Polymeric Compatibilizer Masterbatches on Morphological, Thermal, Mechanical, and Tribological Properties of Polyethylene

Maija Pöllänen, Sami Pirinen, Mika Suvanto, Tuula T. Pakkanen

PII:

S0266-3538(11)00171-0

DOI:

10.1016/j.compscitech.2011.05.009

Reference:

CSTE 4989

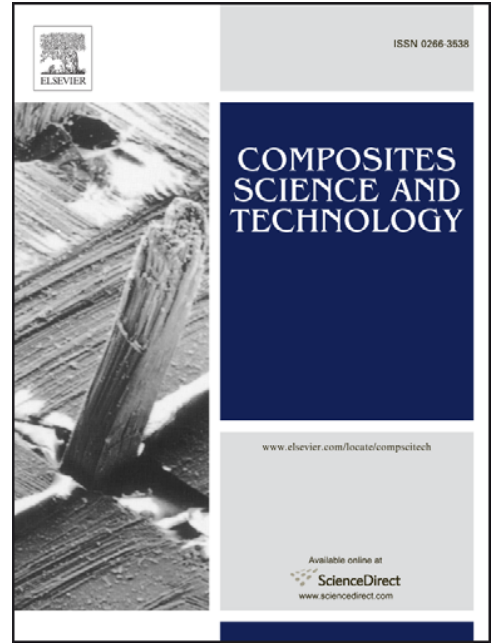

To appear in:

Composites Science and Technology

Received Date:

17 March 2011

Revised Date:

9 May 2011

Accepted Date:

15 May 2011

Please cite this article as: Pöllänen, M., Pirinen, S., Suvanto, M., Pakkanen, T.T., Influence of Carbon NanotubePolymeric Compatibilizer Masterbatches on Morphological, Thermal, Mechanical, and Tribological Properties of Polyethylene, Composites Science and Technology (2011), doi: 10.1016/j.compscitech.2011.05.009

This is a PDF file of an unedited manuscript that has been accepted for publication. As a service to our customers we are providing this early version of the manuscript. The manuscript will undergo copyediting, typesetting, and review of the resulting proof before it is published in its final form. Please note that during the production process errors may be discovered which could affect the content, and all legal disclaimers that apply to the journal pertain. 
Influence of Carbon Nanotube-Polymeric Compatibilizer Masterbatches on Morphological, Thermal, Mechanical, and Tribological Properties of Polyethylene

Maija Pöllänen, Sami Pirinen, Mika Suvanto, and Tuula T. Pakkanen*

Department of Chemistry, University of Eastern Finland, P.O. Box 111, 80101 Joensuu,

Finland

*Corresponding author. Tel.: +358 132513340; fax: +358132513390

E-mail address: Tuula.Pakkanen@uef.fi (T.T. Pakkanen).

\begin{abstract}
Study was made of the effect of multiwall carbon nanotubes (MWCNTs) and polymeric compatibilizer on thermal, mechanical, and tribological properties of high density polyethylene (HDPE). The composites were prepared by melt mixing in two steps. Carbon nanotubes (CNTs) were melt mixed with maleic anhydride grafted polyethylene (PEgMA) as polymeric compatibilizer to produce a PEgMA-CNT masterbatch containing $20 \mathrm{wt} \%$ of CNTs. The masterbatch was then added to HDPE to prepare HDPE nanocomposites with CNT content of 2 or 6 wt.\%. The unmodified and modified (hydroxyl or amine groups) CNTs had similar effects on the properties of HDPE-PEgMA indicating that only noncovalent interactions were achieved between CNTs and matrix. According to SEM studies, single nanotubes and CNT agglomerates (size up to $1 \mu \mathrm{m}$ ) were present in all nanocomposites regardless of content or modification of CNTs. Addition of CNTs to HDPE-PEgMA increased decomposition temperature, but only slight changes were observed in crystallization temperature, crystallinity, melting temperature, and coefficient of linear thermal expansion (CLTE). Young's modulus and tensile strength of matrix clearly increased, while elongation at break decreased. Measured values of Young's moduli
\end{abstract}


of HDPE-PEgMA-CNT composites were between the values of Young's moduli for longitudinal $\left(\mathrm{E}_{11}\right)$ and transverse $\left(\mathrm{E}_{22}\right)$ direction predicted by Mori-Tanaka and Halpin-Tsai composite theories. Addition of CNTs to HDPE-PEgMA did not change the tribological properties of the matrix. Because of its higher crystallinity, PEgMA possessed significantly different properties from HDPE matrix: better mechanical properties, lower friction and wear, and lower CLTE in normal direction. Interestingly, the mechanical and tribological properties and CLTEs of HDPE-PEgMA-CNT composites lie between those of PEgMA and HDPE.

Keywords: A. Carbon nanotubes; A. Polymer-matrix composites (PMCs); B. Thermal properties; B. Mechanical properties; B. Friction/wear

\section{Introduction}

Polymer nanocomposites have been extensively studied in the past few decades. Nanomaterials have been added to polymers with the aim of creating high-performance lightweight materials with combinations of properties tailored for specific commercial applications. With their unique physical and mechanical properties and high aspect ratio, carbon nanotubes are promising nanofillers for the reinforcement of polymers [1-7].

Polyolefin nanocomposites are fabricated by in situ polymerization, solution mixing, and, of interest here, melt mixing. Melt mixing is a simple and economical method since the nanofiller is added directly to the polymer melt. The challenge in melt mixing is to achieve a good dispersion of the nanofiller through shear forces and a strong coupling between nanofiller and matrix [6,7]. Strong coupling between filler and matrix is particularly difficult to achieve with non-polar polymers like polyethylene and polypropylene. Chemical compatibility of nanofiller and polyolefin matrix has been 
enhanced and the dispersion of nanofiller improved through the addition of polymeric compatibilizers such as maleic anhydride grafted polymers [8-10]. Yang et al. [8] enhanced the compatibility and dispersion of MWCNTs and polyethylene by melt blending of amine-functionalized nanotubes with PEgMA. Grafting PEgMA onto CNT improved the mechanical properties of composites. Xie et al. [9] used maleic anhydride grafted styrene(ethylene-co-butylene)-styrene copolymer (MA-SEBS) as compatibilizer in thermal studies on ultrahigh molecular mass polyethylene-carbon nanotube composites. Prashantha et al. [10] found maleic anhydride grafted polypropylene (PPgMA) to improve the dispersion of MWCNT in polypropylene. By wrapping around MWCNTs, the PPgMA gave higher modulus and strength.

Increase in Young's modulus $[8,11-18]$ and decrease in elongation at break $[8,12,14,18-20]$ have frequently been reported for CNT-polyethylene nanocomposites. Thermal properties such as melting and crystallization temperatures and crystallinity are reported to change slightly or not at all upon CNT addition [8,15-19,21]. Besides mechanical properties, thermal expansion and tribological behavior of composites are critical factors in many applications. Thermal expansion is much higher for polymers than for ceramics or metals and may cause problems in junctions between polymers and ceramics or metals, especially where materials are used over a wide range of temperatures. Friction and wear behavior of materials are highly dependent on ambient conditions and measuring parameters. In general, HDPE has a good wear resistance and low friction coefficient [22]. The addition of nanotubes has been reported to improve the wear rate of PE but the effect on friction coefficient is not straightforward [23-25]. 
To predict the properties of nanocomposites is challenging since the result is influenced by a diversity of factors including type, purity, size, defects, and aspect ratio of the filler; levels of dispersion and loading; processing method; polymer matrix; and interactions between matrix and filler. Models based on Mori-Tanaka and Halpin-Tsai composite theories are widely used to predict the elastic properties of polymer composites containing micron-sized fillers. These theories have also been used to predict Young's modulus of composites with nano-sized fillers since only the shape and volume fraction of the filler are needed for modeling of the elastic modulus. Both theories assume that the filler is firmly bonded to the matrix, and the effect of the filler-matrix interface is not considered. The principles and details of the theories can be found in the literature [5,2631].

We studied the influence of unmodified and modified $\left(\mathrm{OH}\right.$ and $\left.\mathrm{NH}_{2}\right)$ multiwall carbon nanotubes on the mechanical, morphological, thermal, and tribological properties of HDPE. PEgMA was used as a polymeric compatibilizer to improve the adhesion between the CNTs and HDPE. The effect of CNTs on the mechanical properties of polyethylene has received considerable attention, but properties such as thermal dimensional stability and tribological behavior are important, as well.

\section{Materials and methods}

\subsection{Materials}

High density polyethylene (HDPE, No CG8410) was purchased from Borealis Polymers Oy. The melt flow rate of $\operatorname{HDPE}\left(\rho=0.941 \mathrm{~g} / \mathrm{cm}^{3}\right)$ was $7.5 \mathrm{~g} / 10 \mathrm{~min}$ and the melting range

was $110-140{ }^{\circ} \mathrm{C}$. HDPE had a weight average molecular mass $\left(\mathrm{M}_{\mathrm{w}}\right)$ of $300 \mathrm{~kg} / \mathrm{mol}$ and a polydispersity index, Mw/Mn (PDI), of 29. Molar mass distributions of HDPE and PEgMA 
were measured with an Alliance GPCV 2000 in 1,2,4-trichlorobenzene at $140{ }^{\circ} \mathrm{C}$. Columns were styragel HT3-5. Maleic anhydride grafted polyethylene (PEgMA, Polybond 3009) with maleic anhydride level of 1 wt.\% was supplied from Crompton Uniroyal Chemical. The melt flow rate of PEgMA $\left(\rho=0.95 \mathrm{~g} / \mathrm{cm}^{3}\right)$ was $5.6 \mathrm{~g} / 10 \mathrm{~min}$ and the melting point was $127^{\circ} \mathrm{C}$. PEgMA had $\mathrm{M}_{\mathrm{w}}$ of $74 \mathrm{~kg} / \mathrm{mol}$ and PDI of 6. CNTs, purchased from Nanocyl, had been produced via the catalytic carbon vapor deposition (CCVD) process and purified afterwards. MWCNT (Nanocyl 3150), MWCNT-OH (Nanocyl 3153, functionalization level < 6 atomic.\%.), and MWCNT- $\mathrm{NH}_{2}$ (Nanocyl 3152, functionalization level < 0.5 atomic.\%.) had average diameter of $10 \mathrm{~nm}$, average length less than $1 \mu \mathrm{m}$, and carbon purity higher than 95\% (datasheet ref: NC3150DS-01 June 2005).

\subsection{Preparation of composites}

The polymeric compatibilizer (PEgMA) and carbon nanotubes (CNTs) were mixed with a conical twin-screw microcompounder (DSM Midi 2000) to produce PEgMA-CNT masterbatches with CNT content of $20 \mathrm{wt} . \%$. The melt mixing of masterbatches was done with a screw temperature of $150^{\circ} \mathrm{C}$, a screw rotation speed of $150 \mathrm{rpm}$, and a mixing time of 5 min. The masterbatches were granulated and blended with HDPE in the melt compounder to produce the final composites, and then injection molded to test specimens with a DSM microinjection molding instrument. The CNT-wt.\% in the final composites

was 2 or 6 . The melt mixing of composites was done with a screw temperature of $200^{\circ} \mathrm{C}$, a screw rotation speed of $100 \mathrm{rpm}$, and a mixing time of $5 \mathrm{~min}$, and the injection molding with a temperature of feed unit of $180^{\circ} \mathrm{C}$, a mold temperature of $40^{\circ} \mathrm{C}$, and a piston pressure of 5-6 bar. The test specimens produced by injection molding used in the mechanical, CLTE, and SEM investigations were $1.5 \mathrm{~mm}$ thick, $5.0 \mathrm{~mm}$ wide, and had a 
gauge length of $35 \mathrm{~mm}$, while the disk-shaped specimens used in tribological studies were $1.5 \mathrm{~mm}$ thick and $25 \mathrm{~mm}$ in diameter.

\subsection{Characterization}

Dispersions of CNTs in PEgMA and HDPE-PEgMA were characterized by scanning electron microscopy (Hitachi S-4800). All samples were coated with $\mathrm{Pt}-\mathrm{Pd}$ alloy (layer thickness of 1.5-2 nm) to facilitate the measurements. The CNTs in PEgMA were examined on fracture surfaces of the masterbatches broken at the temperature of liquid nitrogen. For characterization of CNTs in HDPE-PEgMA and in PEgMA, sample pieces were pretreated by reactive ion etching with oxygen as reactive etching gas. Etching was carried out with an Oxford Plasmalab 80 Plus reactive ion etching system where the working pressure in the chamber was 80 mTorr and the oxygen flow was 20 SCCM. The etching time was $30 \mathrm{~s}$, and the etching power was $100 \mathrm{~W}$ for HDPE-PEgMA-CNT composites, and $300 \mathrm{~W}$ for PEgMA-CNT masterbatches.

Thermogravimetric analysis (TGA) was done to determine the amounts of CNTs and the decomposition temperatures of the masterbatches and composites. TGA measurements were carried out on a Mettler Toledo TGA/STDA851 ${ }^{\mathrm{e}}$ under a nitrogen gas flow $(50 \mathrm{ml} / \mathrm{min})$, between 25 and $600{ }^{\circ} \mathrm{C}$, with a heating rate of $20{ }^{\circ} \mathrm{C} / \mathrm{min}$. Three measurements were made of each sample.

Differential scanning calorimetry (DSC) was performed on a Mettler Toledo DSC823 ${ }^{\mathrm{e}}$ under a nitrogen gas flow $(50 \mathrm{ml} / \mathrm{min})$ between 25 and $200{ }^{\circ} \mathrm{C}$ with heating rate of $10^{\circ} \mathrm{C} / \mathrm{min}$. The DSC program included two heating-cooling cycles. The melting and crystallization temperatures and the crystallinity were determined from the second heatingcooling cycle. The determined values are the averages of three measurements. 
Thermomechanical analysis (TMA), done to determine the coefficient of linear thermal expansion (CLTE) of the composites containing unmodified MWCNTs, was carried out on a Mettler Toledo TMA/SDTA841 ${ }^{\mathrm{e}}$ with a ball-point probe $(3.0 \mathrm{~mm})$. Measurements were performed between two quartz disks $(\mathrm{d}=6 \mathrm{~mm})$ under a nitrogen gas flow $\left(30 \mathrm{ml} / \mathrm{min}\right.$ ) between 40 and $120{ }^{\circ} \mathrm{C}$ with a heating rate of $5{ }^{\circ} \mathrm{C} / \mathrm{min}$ and normal load of $0.05 \mathrm{~N}$. The TMA program included two heating-cooling cycles, and the CLTE was recorded from the second heating. TMA measurements were made in injection molding direction (flow) and perpendicular to the injection direction (normal) using tensile test specimens, which were cut, vertical to the injection direction, into pieces of $3.5 \mathrm{~mm}$ from the middle. Hence each specimen had a height of 1.5, depth of 5, and length of $3.5 \mathrm{~mm}$. TMA measurements were made first in flow and then in normal direction. The CLTE value is the average of three measurements.

Mechanical testing of composites was carried out on material testing equipment (Zwick Z010-TH2A model 2001) with a crosshead speed of $50 \mathrm{~mm} / \mathrm{min}$. Calculations were performed with TestXpert version 8.1 software. Eight standard tensile specimens were tested for each series. The Young's modulus was determined from the elastic region of the stress-strain curve. Tensile strength was the maximum at yield point for the CNT composites and PEgMA, and the maximum of the stress-strain curve for HDPE and HDPE-PEgMA references.

Measured Young's moduli of composites were compared with values predicted by Mori-Tanaka and Halpin-Tsai composite theories. According to a model based on MoriTanaka composite theory and reformulated by Tandon and Weng [28], the longitudinal and transverse moduli $\left(\mathrm{E}_{11}\right.$ and $\left.\mathrm{E}_{22}\right)$ of composites can be expressed with equations 
$\mathrm{E}_{11} / \mathrm{E}_{\mathrm{m}}=\mathrm{A} /\left[\mathrm{A}+\Phi_{\mathrm{f}}\left(\mathrm{A}_{1}+2 v_{\mathrm{m}} \mathrm{A}_{2}\right)\right]$

$\mathrm{E}_{22} / \mathrm{E}_{\mathrm{m}}=2 \mathrm{~A} /\left[2 \mathrm{~A}+\Phi_{\mathrm{f}}\left[-2 v_{\mathrm{m}} \mathrm{A}_{3}+\left(1-v_{\mathrm{m}}\right) \mathrm{A}_{4}++\left(1+v_{\mathrm{m}}\right) \mathrm{A}_{5} \mathrm{~A}\right]\right]$

where $E_{\mathrm{m}}$ and $v_{\mathrm{m}}$ are Young's modulus and Poisson's ratio of the matrix and $\Phi_{\mathrm{f}}$ is the volume fraction of the filler. Functions of Eshelby's tensor $\left(A, A_{1}-A_{5}\right)$ depend on properties of the filler and matrix [26-28].

According to the Halpin-Tsai composite theory, the longitudinal and transverse moduli ( $\mathrm{E}_{11}$ and $\left.\mathrm{E}_{22}\right)$ can be calculated with the formulas

$\mathrm{E} / \mathrm{E}_{\mathrm{m}}=\left(1+\zeta \eta \Phi_{\mathrm{f}}\right) /\left(1-\eta \Phi_{\mathrm{f}}\right)$

$\eta=\left(E_{\mathrm{f}} / \mathrm{E}_{\mathrm{m}}-1\right) /\left(\mathrm{E}_{\mathrm{f}} / \mathrm{E}_{\mathrm{m}}+\zeta\right)$

where $\Phi_{\mathrm{f}}$ is the volume fraction of filler and $\mathrm{E}, \mathrm{E}_{\mathrm{f}}$, and $\mathrm{E}_{\mathrm{m}}$ are the Young's moduli of the composite, filler, and matrix. The shaper parameter, $\zeta$, is 2 for $E_{22}$ and $2(1 / d)$ for $E_{11}$, where $1 / \mathrm{d}$ is the aspect ratio of the filler $[5,27,29-30]$.

For randomly oriented composites the equations based on Halpin-Tsai composite theory can be presented as

$\mathrm{E} / \mathrm{E}_{\mathrm{m}}=3 / 8 *\left[\left(1+\zeta \eta_{\mathrm{L}} \Phi_{\mathrm{f}}\right) /\left(1-\eta_{\mathrm{L}} \Phi_{\mathrm{f}}\right)\right]+5 / 8 *\left[\left(1+2 \eta_{\mathrm{T}} \Phi_{\mathrm{f}}\right) /\left(1-\eta_{\mathrm{T}} \Phi_{\mathrm{f}}\right)\right]$

$\eta_{\mathrm{L}}=\left(\mathrm{E}_{\mathrm{f}} / \mathrm{E}_{\mathrm{m}}-1\right) /\left(\mathrm{E}_{\mathrm{f}} / \mathrm{E}_{\mathrm{m}}+\zeta\right)$

$\eta_{\mathrm{T}}=\left(\mathrm{E}_{\mathrm{f}} / \mathrm{E}_{\mathrm{m}}-1\right) /\left(\mathrm{E}_{\mathrm{f}} / \mathrm{E}_{\mathrm{m}}+2\right)$

where $\zeta$ is $2(1 / d)$ and $1 / d$ is the aspect ratio of the filler $[5,31]$.

In the calculations, Poisson's ratio of 0.3 [32-33], density of $2.0 \mathrm{~g} / \mathrm{cm}^{3}[30,34,35]$, Young's modulus of $50 \mathrm{GPa}$ [36-38], and estimated aspect ratio of 100 were used for MWCNTs, and Poisson's ratio of $0.35[39,40]$ and Young's moduli measured for HDPEPEgMA reference samples $(0.66-0.70 \mathrm{GPa})$ were used for the matrix.

Tribological measurements were performed with a CSM Instruments Tribometer using a pin-on-disk geometry. A cylindrical steel pin with diameter of $6 \mathrm{~mm}$ was fixed at a 
45-degree angle toward the disk-shaped sample $(\mathrm{d}=25 \mathrm{~mm}, \mathrm{~h}=1.5 \mathrm{~mm})$ with radius of 8 or $10 \mathrm{~mm}$. The tests were made at room temperature with a linear speed of $0.15 \mathrm{~m} / \mathrm{s}$, normal load of $25 \mathrm{~N}$, and total sliding distance of $500 \mathrm{~m}$. Six measurements were made of each sample, and the average of the measurements was calculated. The friction coefficient $(\mu)$ was observed as an average of values between 0 and $500 \mathrm{~m}$. The wear was calculated as the difference between average penetration depths of 490-500 $\mathrm{m}$ and 90-100 $\mathrm{m}$.

\section{Results and discussion}

\subsection{Dispersion of CNTs in nanocomposites characterized by SEM}

The CNTs in PEgMA-MWCNT masterbatches prepared by melt mixing were characterized by SEM. Images of MWCNT-OH and melt mixed strands of PEgMA and PEgMA-MWCNT-OH(20) masterbatch are shown in Figure 1. Comparisons of the images of cryofractured surfaces (Fig. 1b-1c) and etched surfaces (Fig. 1d-e) of PEgMA and PEgMA-MWCNT-OH do not readily reveal the dispersion at nanoscale because of the high content (20 wt.\%) of CNT in PEgMA. The etched surface of PEgMA is evidently smoother than that of the masterbatch containing nanotubes, however.

Figure 2 presents SEM images of surfaces of HDPE-PEgMA(24) and HDPEPEgMA(24)-MWCNT(6) after reactive oxygen etching, recorded from the middle of tensile test specimens in normal direction. The flow direction in the figure is horizontal. Single MWCNTs and MWCNT agglomerates with a size up to $1 \mu \mathrm{m}$ were present in nanocomposites. Interestingly, the individual nanotubes appear to be orientated in flow direction and perpendicular to the striated surface pattern of the polymer. In all nanocomposites CNTs existed in isolated and agglomerated forms. Modification or content of CNTs seemed to have no effect on size or amount of the CNT agglomerates. 


\subsection{Thermal properties of composites characterized by TGA, DSC, and TMA}

The influence of carbon nanotubes and PEgMA on the thermal properties of HDPE was investigated in terms of decomposition temperature, crystallinity, melting temperature, crystallization temperature, and linear thermal expansion. TGA results show that CNT contents in PEgMA and HDPE-PEgMA agree well with the amounts weighed for the preparation of composites. Incorporation of CNTs into PEgMA and HDPE-PEgMA increased the decomposition temperature (over $10{ }^{\circ} \mathrm{C}$ for $6 \mathrm{wt} . \% \mathrm{CNT}$ addition to $\mathrm{HDPE}-$ PEgMA) indicating that the presence of CNTs hinders the decomposition at high temperatures. Increase of the decomposition temperature of polyethylene by the addition of nanotubes has been reported earlier [18-19,41]. We observed only slight changes in crystallinity, melting temperature, and crystallization temperature when CNTs were added to PEgMA and HDPE-PEgMA. In line with this, other research groups have reported slight or no change in the thermal properties of PE-CNT composites prepared by melt compounding [8,18-19,21]. Crystallinity of PEgMA was over $10 \%$ higher than that of HDPE.

Figure 3 shows the coefficients of linear thermal expansion (CLTEs) of samples from tensile test specimens in temperature range of $40-100{ }^{\circ} \mathrm{C}$ in flow and normal directions. In flow direction, CLTEs of the samples are closely similar, with HDPE showing the lowest value (Fig. 3a). In normal direction, neat PEgMA has the lowest and neat HDPE the highest CLTE, and addition of PEgMA to HDPE causes a decrease in CLTE. In normal direction, the CLTE of HDPE increases faster than the CLTE of PEgMA as a function of temperature (Fig. 3b). Since PEgMA has a higher crystallinity than HDPE, the microscopic structures of the injection molded specimens differ, and CLTEs of HDPE 
and PEgMA are dissimilar in both flow and normal directions. Further, since the CLTE values of HDPE-PEgMA-MWCNT composites are independent of the CNT content in both flow and normal directions, we can conclude that the addition of MWCNTs has no influence on the morphology of the matrix.

The main factors influencing the CLTE of polyethylene are the ratio of crystalline regions to amorphous regions and the orientation of the crystallographic c-axis (chain axis) relative to the measuring direction. The crystalline regions expand less than the disordered regions because of the restricted freedom of chain movements in crystalline regions. The crystallographic c-axis is parallel to the carbon-carbon polymer chain and therefore has lower CLTE than the crystallographic a- and b-axes [22].

The difference in the CLTEs of the measured samples in flow and normal direction may be explained by the crystallographic orientation or the anisotropic multilayer structure of injection molded specimens or both. Conventional injection molding of polyethylene leads to skin-core structure since contact of hot polyethylene melt with the cold mold walls produces a temperature gradient and high stress for the melt, with resulting high orientation of polyethylene chains near the surface. In the skin layer, polyethylene chains are oriented in flow direction and form lamellas, while in the core the lamellas appear in the form of spherulitic crystals [42-43]. Four distinct layers have been characterized in an injection molded specimen of linear polyethylene [42]. Properties of the polymer, the processing parameters, and the geometry of the mold influence the formation of these layers and the orientation of polymer chains [42-44]. Moy and Kamal [45] found that maximum crystallinity of injection molded polyethylene occurs at the center, while maximum 
orientation occurs near the surface. Predominantly it is the crystallographic a-axis that is oriented in flow direction, but the orientation of the c-axis in flow direction increases toward the surface [45].

In the measurements in flow direction the measured surface is the cross-sectional area of the tensile test specimen, and adjacent layers are expanding independently. Since the thermal expansion is measured between two quartz disks, the layer with highest CLTE determines the final CLTE value. In normal direction, however, the layers lie one upon the other, forming a sandwich-like structure, and all layers influence the final value.

\subsection{Mechanical properties of composites}

Mechanical properties of HDPE-PEgMA-CNT composites and reference samples are presented in Figure 4. Young's modulus and the tensile strength of HDPE-PEgMA increased and breaking strength and elongation at break decreased upon the addition of CNTs. Similar results were obtained for unmodified and modified CNTs indicating either that covalent bonding between functional groups of CNTs and the maleic anhydride group of PEgMA did not take place or that the level of reacted groups was insignificant. Note that, because of its higher crystallinity, PEgMA had clearly higher Young's modulus, tensile strength, breaking strength, and elongation at break than HDPE did.

Our results showed Young's modulus and tensile strength to increase upon addition

of CNTs to HDPE-PEgMA even though the level of crystallinity remained unchanged. CNT nanodispersion in composites is not optimal (see SEM findings), and interactions between matrix and nanotubes appear to occur merely as non-covalent bonding. Moreover, the aspect ratio of the nanotubes was only 100, whereas the typical aspect ratio of CNTs is 
300-1000 [6]. At the same time, the small tube diameter and short length may be considered to facilitate the dispersion. Decreases in breaking strength and elongation at break were probably due to the presence of CNT agglomerates in the nanocomposites. Agglomerates may work as initiation sites for failure or accelerate the final breakage [7]. Similar trends in mechanical properties have been reported for $\mathrm{CNT}_{-}$reinforced UHMWPE composites [14]. Chrissafis et al. [18] found addition of $2.5 \mathrm{wt} \%$ of MWCNT to HDPE to increase Young's modulus (30\%) and decrease elongation at break and breaking strength, while tensile yield strength was unchanged.

Increased Young's modulus and tensile strength indicate stress transfer between the HDPE-PEgMA matrix and CNTs. In the case of non-covalent interactions, adhesion can be produced by van der Waals interactions or mechanical interlocking or both. Mechanical interlocking may be promoted by entanglements between CNTs and the matrix and surface defects of CNTs, as well as by the thermal mismatch of CNTs and polyethylene. Moreover, the linear structure of CNTs may enhance the mixing of CNTs with HDPE and PEgMA chains [46]. In our studies, similar tensile strengths were obtained for unmodified and modified CNTs, which suggets that even in the case where interactions in nanocomposites involve only non-covalent bonding, the addition of CNT masterbatch to polyethylene leads to higher tensile strength. Clearly, when both single CNTs and agglomerates of CNT exist in a composite, properties will be the result of both. Evidently, single CNTs have a reinforcing effect on composites, while agglomerates may act as defects and decrease the strength and toughness. 
Experimental Young's moduli of HDPE-PEgMA-CNT composites were compared with Young's moduli predicted by models based on the theories of Mori-Tanaka and Halpin-Tsai (Table 1) CNTs are reported $[7,47]$ to have very high Young's modulus, up to $1 \mathrm{TPa}$; for arc-grown MWCNTs, for example, Young's moduli are in the range of 270-950 GPa [47]. Note, however, that defects in CNTs significantly reduce Young's moduli. Currently, large-scale production of CNTs is mostly done by chemical vapor deposition (CVD) process, which produces defects in CNTs. For CVD-grown MWCNTs, Young's moduli are lower than $100 \mathrm{GPa}[36,37]$ and values are strongly dependent on tube diameter [38]. For our calculations, therefore, we used a Young's modulus of 50 GPa for MWCNTs.

Measured values of Young's moduli were lower than the predicted values for longitudinal directions $\left(\mathrm{E}_{11}\right)$ and higher than the predicted values for transverse directions $\left(\mathrm{E}_{22}\right)$, where predicted values were obtained by Mori-Tanaka and Halpin-Tsai theories. Further, the measured values were lower than the Young's moduli predicted by the model based on the theory of Halpin-Tsai for randomly oriented fibers. These results indicate that only moderate coupling was achieved between carbon nanotubes and the matrix. Moreover, the presence of CNT agglomerates may reduce the functional aspect ratio of the filler, resulting in lower modulus. In addition, melt compounding shortens nanotubes from the initial length [48]. Interestingly, increase in CNT content from 2 to 6 wt.\% was accompanied with only a moderate increase in measured Young's moduli compared to the moduli predicted by Halpin-Tsai theory for randomly oriented fibers (Table 1). Evidently stress transfer between CNTs and the matrix is less effective at the higher CNT concentrations. 


\subsection{Tribological properties of composites}

Wear and friction properties of HDPE-PEgMA-CNT nanocomposites and reference samples, obtained by pin-on-disk geometry, are presented in Figure 5. As expected from its higher crystallinity and higher Young's modulus, the results show PEgMA to have a clearly lower friction coefficient and higher wear resistance than HDPE. Additions of CNTs to HDPE-PEgMA caused only slight changes in the tribological properties. Moreover, results were similar for composites containing unmodified and modified CNTs. It should be noted that tribological measurements were made in normal direction, and the results are comparable to the CLTE results obtained by TMA in the same direction. In normal direction, PEgMA exhibits the lowest and HDPE the highest CLTE, friction coefficient, and wear.

\section{Conclusions}

In studies of HDPE-PEgMA-CNT nanocomposites prepared by two-step melt compounding. SEM results indicated the presence of CNTs in HDPE-PEgMA in isolated and agglomerated form. In the surface layer of tensile test specimens, isolated CNTs appeared to be orientated in flow direction and perpendicular to the striated pattern of the matrix. Since the hydroxyl and amine modifications of CNTs had no notable effect on the properties of composites, we deduce that no reactions took place between functional groups (hydroxyl or amine) of modified CNTs and anhydride groups of PEgMA. The interactions between nanotubes and polymer matrix appear to involve non-covalent bonding. With the moderate interaction and adequate dispersion of nanotubes, increases in Young's modulus, tensile strength, and decomposition temperature were obtained with no major changes in thermal or tribological properties of HDPE-PEgMA. Theoretical predictions supported our 
experimental findings that non-covalent interaction between CNTs and matrix allows stress transfer from matrix to nanotubes, thereby increasing Young's modulus.

\section{Acknowledgments}

Financial support from the Finnish Funding Agency for Technology and Innovation (Tekes) and the European Union/European Regional Development Fund is gratefully acknowledged.

\section{References}

[1] Thostenson ET, Ren Z, Chou T-W. Advances in the science and technology of carbon nanotubes and their composites: a review. Compos Sci Technol 2001;61:1899-1912.

[2] Khare R, Bose S. Carbon nanotube based composites-a review. J Miner Mater Charact Eng 2005;4(1):31-46.

[3] Xie X-L, Mai Y-W, Zhou X-P. Dispersion and alignment of carbon nanotubes in polymer matrix: a review. Mat Sci Eng R 2005;49:89-112.

[4] Thostenson ET, Li C, Chou T-W. Nanocomposites in context. Compos Sci Technol 2005;65:491-516.

[5] Coleman JN, Khan U, Blau WJ, Gun'ko YK. Small but strong: A review of the mechanical properties of carbon nanotube-polymer composites. Carbon 2006;44:1624-1652.

[6] Moniruzzaman M, Winey KI. Polymer nanocomposites containing carbon nanotubes. Macromolecules 2006;39:5194-5205.

[7] Ajayan PM, Schadler LS, Braun PV. Nanocomposite Science and Technology. Wiley-VCH: Weinheim; 2003, p.77-153.

[8] Yang B-X, Pramoda KP, Xu GQ, Goh SH. Mechanical reinforcement of polyethylene using polyethylene-grafted multiwalled carbon nanotubes. Adv Funct Mater 2007;17:2062-2069.

[9] Xie XL, Alous K, Zhou XP, Zeng FD. Ultrahigh molecular mass polyethylene/carbon nanotubes composites. J Therm Anal Calorim 2003;74:317-323.

[10] Prashantha K, Soulestin J, Lacrampe MF, Claes M, Dupin G, Krawczak P. Multi-walled carbon nanotube filled polypropylene nanocomposites based on masterbatch route: improvement of dispersion and mechanical properties through PP-g-MA addition. Express Polym Lett 2008;2(10):735-745. 
[11] Zhang Q, Rastogi S, Chen D, Lippits D, Lemstra PJ. Low percolation threshold in singlewalled carbon nanotube/high density polyethylene composites prepared by melt processing technique. Carbon 2006;44:778-785.

[12] Xiao KQ, Zhang LC, Zarudi I. Mechanical and rheological properties of carbon nanotubereinforced polyethylene composites. Compos Sci Technol 2007;67:177-182.

[13] Ruan SL, Gao P, Yang XG, Yu TX. Toughening high performance ultrahigh molecular weight polyethylene using multiwalled carbon nanotubes. Polymer 2003;44:5643-5654.

[14] Mierczynska A, Mayne-L'Hermite M, Boiteux G, Jeszka JK. Electrical and mechanical properties of carbon nanotube/ultrahigh-molecular-weight polyethylene composites prepared by a filler prelocalization method. J Appl Polym Sci 2007;105:158-168.

[15] Kanagaraj S, Varanda FR, Zhil'tsova TV, Oliveira MSA, Simões JAO. Mechanical properties of high density polyethylene/carbon nanotube composites. Compos Sci Technol 2007;67:30713077.

[16] Gorrasi G, Sarno M, Di Bartolomeo A, Sannino D, Ciambelli P, Vittoria V. Incorporation of carbon nanotubes into polyethylene by high energy ball milling: morphology and physical properties. J Polym Sci Polym Phys 2007;45:597-606.

[17] Vega JF, Martinez-Salazar J, Trujillo M, Arnal ML, Müller AJ, Bredeau S, Dubois Ph. Rheology, processing, tensile properties, and crystallization of polyethylene/carbon nanotube nanocomposites. Macromolecules 2009;42:4719-4727.

[18] Chrissafis K, Paraskevopoulos KM, Tsiaoussis I, Bikiaris D. Comparative study of the effect of different nanoparticles on the mechanical properties, permeability, and thermal degradation mechanism of HDPE. J Appl Polym Sci 2009;114:1606-1618.

[19] McNally T, Pötschke P, Halley P, Murphy M, Martin D, Bell SEJ, Brennan GP, Bein D, Lemoine P, Quinn JP. Polyethylene multiwalled carbon nanotube composites. Polymer 2005;46:8222-8232.

[20] Zhao D, Lei Q, Qin C, Bai X. Melt process and performance of multi-walled carbon nanotubes reinforced LDPE composites. Pigm Resin Technol 2006;35(6):341-345.

[21] Nobile MR, Simon GP, Valentino O, Morcom M. Rheological and structure investigation of melt mixed multi-walled carbon nanotube/PE composites. Macromol Symp 2007;247:78-87.

[22] Peacock AJ. Handbook of Polyethylene: Structures, Properties, and Applications. Marcel Dekker: New York; 2000, Chapter 5. Properties of Polyethylene, p. 123-240.

[23] Zoo Y-S, An J-W, Lim D-P, Lim D-S. Effect of carbon nanotube addition on tribological behavior of UHMWPE. Triboll Lett 2004, 16, 305-309. 
[24] Xue Y, Wu W, Jacobs O, Schädel B. Tribological behavior of UHMWPE/HDPE blends reinforced with multi-wall carbon nanotubes. Polym Test 2006;25:221-229.

[25] Johnson BB, Santare MH, Novotny JE, Advani SG. Wear behavior of carbon nanotube/high density polyethylene composites. Mech Mater 2009;41:1108-1115.

[26] Mori T, Tanaka K. Average stress in matrix and average elastic energy of materials with misfitting inclusions. Acta Metall 1973;21:571-574.

[27] Fornes TD, Paul DR Modeling properties of nylon 6/clay nanocomposites using composite theories. Polymer 2003;44:4993-5013.

[28] Tandon GP, Weng GJ. The effect of aspect ratio of inclusions on the elastic properties of unidirectionally aligned composites. Polym Compos 1984;5(4):327-333.

[29] Halpin J, Kardos J. The Halpin-Tsai equations: a review. Polym Eng Sci 1976;16(5):344-352.

[30] Thostenson ET, Chou T-W. On the elastic properties of carbon nanotube-based composites: modeling and characterization. J Phys D Appl Phys 2003;36:573-582.

[31] McNally T, Boyd P, McGlory C, Bien D, Moore I, Millar B, Davidson J, Carroll T. Recycled carbon fiber filled polyethylene composites. J Appl Polym Sci 2008;107:2015-2021.

[32] Li K, Saigal S. Micromechanical modeling of stress transfer in carbon nanotubes reinforced polymer composites. Mat Sci Eng A 2007;457:44-57.

[33] Lu JP. Elastic properties of single and multilayered nanotubes. J Phys Chem Solids 1997;58(11):1649-1652.

[34] De Rosa IM, Dinescu A, Sarasini F, Sarto MS, Tamburrano A. Effect of short carbon fibers and MWCNTs on microwave absorbing properties of polyester composites containing nickelcoated carbon fibers. Compos Sci Technol 2010;70:102-109.

[35] Seyhan AT, Tanoğlu M, Schulte K. Tensile mechanical behavior and fracture toughness of MWCNT and DWCNT modified vinyl-ester/polyester hybrid nanocomposites produced by 3-roll milling. Mat Sci Eng A 2009;523:85-92.

[36] Salvetat J-P, Kulik AJ, Bonard J-M, Briggs GAD, Stöckli T, Météniér K, Bonnamy S, Béguin F, Burnham NA, Forró L. Elastic modulus of ordered and disordered multiwalled carbon nanotubes. Adv Mater 1999;11(2):161-165.

[37] Lukić B, Seo JW, Couteau E, Lee K, Gradečak S, Berkecz R, Hernadi K, Delpeux S, Cacciaguerra T, Béguin F, Fonseca A, Nagy JB, Csányi G, Kis A, Kulik AJ, Forró L. Elastic modulus of multi-walled carbon nanotubes produced by catalytic chemical vapour deposition. Appl Phys A 2005;80:695-700. 
[38] Lee K, Lukić B, Magrez A, Seo JW, Briggs GAD, Kulik AJ, Forró L. Diameter-dependent elastic modulus supports the metastable-catalyst growth of carbon nanotubes. Nanoletters 2007;7(6):1598-1602.

[39] Jo C, Naguib HE. Constitutive modeling of HDPE polymer/clay nanocomposites foams. Polymer 2007;48:3349-3360.

[40] Bliznakov ED, White CC, Shaw MT. Mechanical properties of blends of HDPE and recycled urea-formaldehyde resin. J Appl Polym Sci 2000;77:3220-3227.

[41] Barus S, Zanetti M, Bracco P, Musso S, Chiodoni A, Tagliaferro A. Influence of MWCNT morphology on dispersion and thermal properties of polyethylene nanocomposites. Polym Degrad Stabil 2010;95:756-762.

[42] Tan V, Kamal MR. Morphological zones and orientation in injection-molded polyethylene. J Appl Polym Sci 1978;22:2341-2355.

[43] Katti SS, Schultz JM. The microstructure of injection-molded semicrystalline polymers: a review. Polym Eng Sci 1982;22(16):1001-1017.

[44] Ben Daly H, Sanschagrin B, Nguyen KT, Cole KC. Effect of polymer properties on the structure of injection-molded parts. Polym Eng Sci 1999;39(9):1736-1751.

[45] Moy FH, Kamal MR. Crystalline and amorphous orientations in injection molded polyethylene. Polym Eng Sci 1980;20(14):957-964.

[46] Liao K, Ren Y, Xiao T in Polymer nanocomposites, ed. by Mai Y-W and Yu Z-Z. Woodhead Publishing: Cambridge; 2006, Chapter 13.3. Carbon nanotube- polymer interface, p.337-346.

[47] Yu M-F, Lourie O, Dyer MJ, Moloni K, Kelly TF, Ruoff RS. Strength and breaking mechanism of multiwalled carbon nanotubes under tensile load. Science, 2000;287:637-640.

[48] Krause B, Boldt R, Pötschke P. A method for determination of length distributions of multiwalled carbon nanotubes before and after melt processing. Carbon 2011;49:1243-1247. 
Table 1. Measured and predicted Young's moduli of the MWCNT composites.

\begin{tabular}{|c|c|c|c|c|}
\hline \multirow[b]{2}{*}{ Sample (wt.\% in composite) } & \multicolumn{4}{|c|}{ Young's modulus (GPa) } \\
\hline & Experimental & $\begin{array}{l}\text { Mori-Tanaka } \\
\text { theory }\end{array}$ & $\begin{array}{l}\text { Halpin-Tsai } \\
\text { theory }\end{array}$ & $\begin{array}{l}\text { Halpin-Tsai } \\
\text { theory for } \\
\text { randomly } \\
\text { oriented } \\
\text { fibers }\end{array}$ \\
\hline & & $\mathbf{E}_{11}$ & $\mathbf{E}_{11}$ & $\mathbf{E}$ \\
\hline HDPE & $0.66 \pm 0.03$ & & & \\
\hline HDPE-PEgMA(8) & $0.66 \pm 0.04$ & & & \\
\hline HDPE-PEgMA(24) & $0.70 \pm 0.03$ & & & \\
\hline HDPE-PEgMA(8)-MWCNT(2) & $0.74 \pm 0.01$ & & & \\
\hline HDPE-PEgMA(8)-MWCNT-OH(2) & $0.76 \pm 0.08$ & 0.90 & 0.68 & 0.80 \\
\hline HDPE-PEgMA(8)-MWCNT-NH 2 (2) & $0.75 \pm 0.02$ & & & \\
\hline HDPE-PEgMA(24)-MWCNT(6) & $0.90 \pm 0.04$ & & & \\
\hline HDPE-PEgMA(24)-MWCNT-OH(6) & $0.93 \pm 0.05$ & 1.28 & 1.78 & 1.14 \\
\hline HDPE-PEgMA(24)-MWCNT-NH $2(6)$ & $0.90 \pm 0.02$ & & & \\
\hline
\end{tabular}




\section{Figure captions}

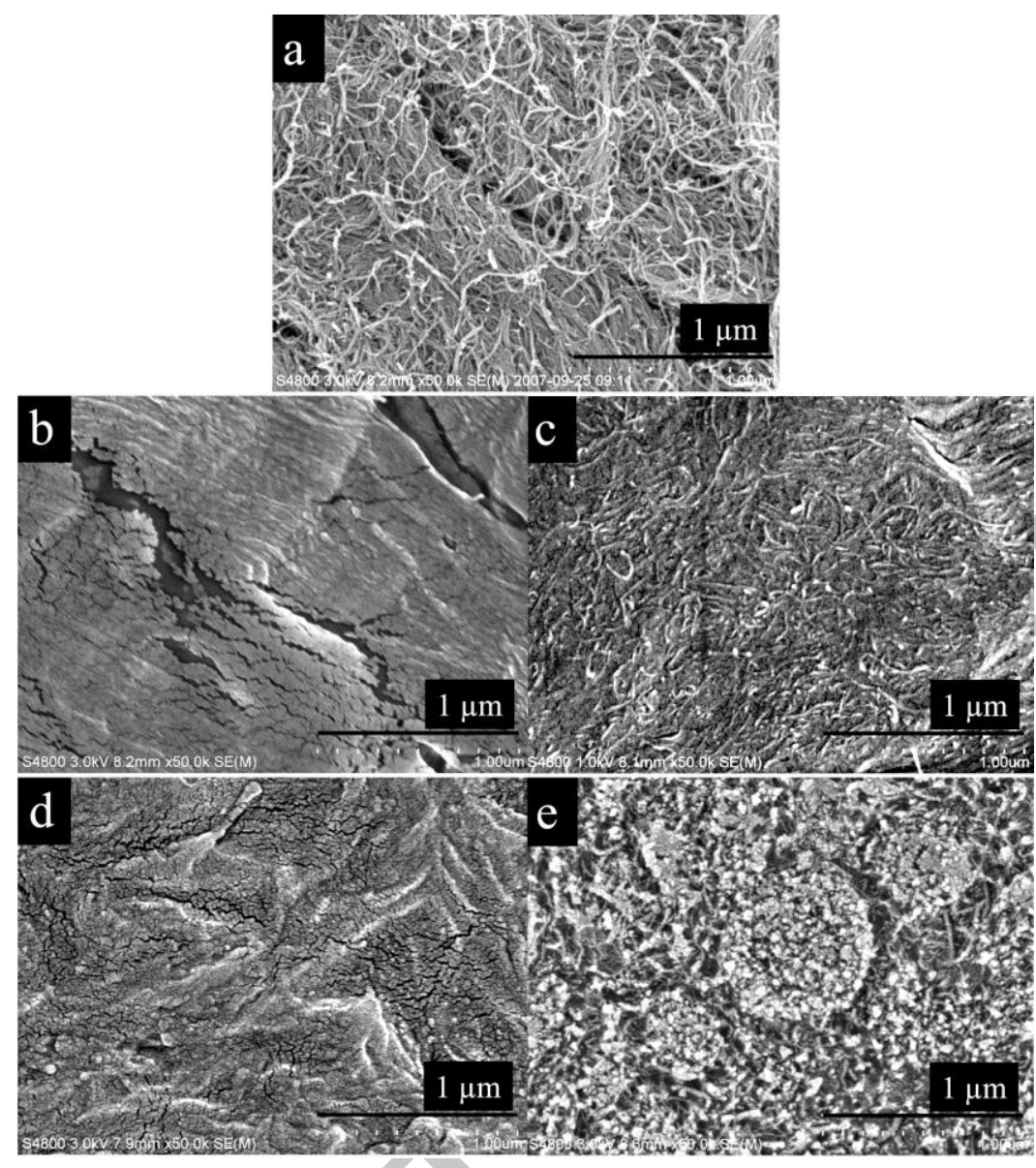

Figure 1. SEM images of MWCNT-OH (a), fracture surfaces of PEgMA (b) and PEgMAMWCNT-OH (20) masterbatch (c), and etched surfaces of PEgMA (d) and PEgMAMWCNT-OH (20) masterbatch (e). 


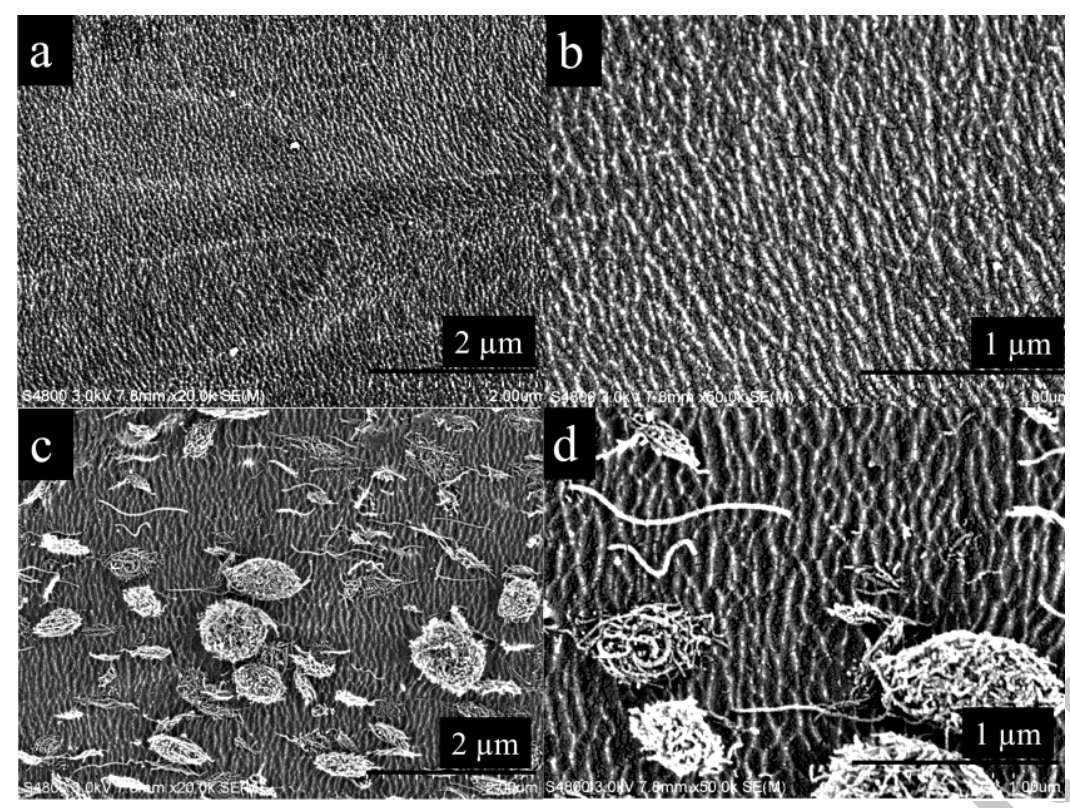

Figure 2. SEM images of etched tensile test specimens of HDPE-PEgMA (24) (a,b) and HDPE-PEgMA(24)-MWCNT(6) (c,d) recorded in normal direction. Flow direction is horizontal.
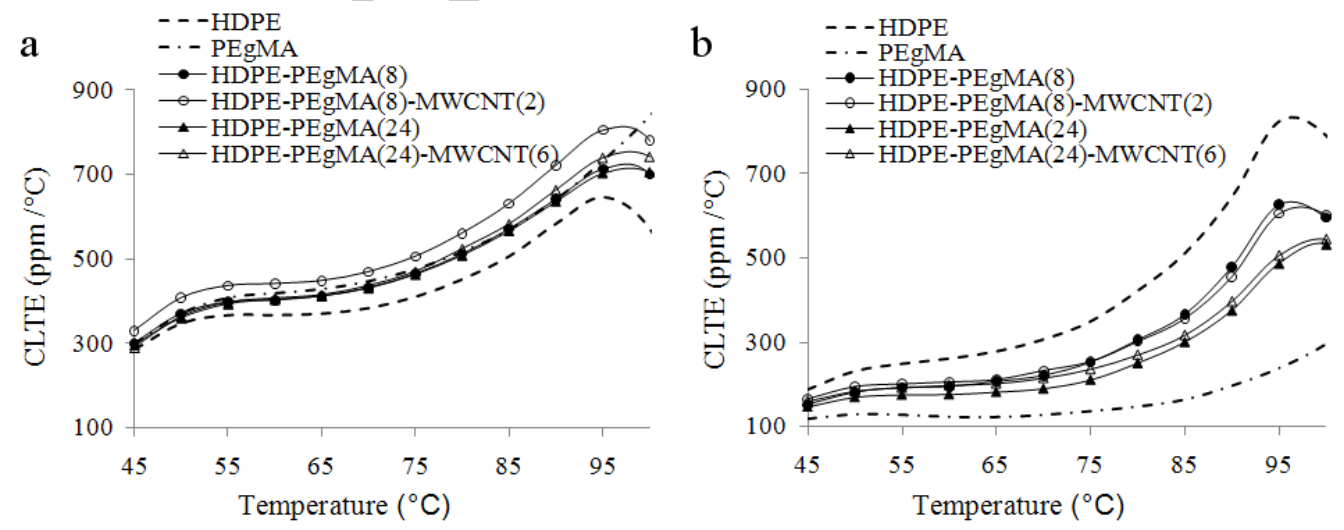

Figure 3. Coefficients of linear thermal expansion (CLTE) of HDPE, PEgMA, and HDPEPEgMA-MWCNT composites in flow (a) and normal (b) directions. 

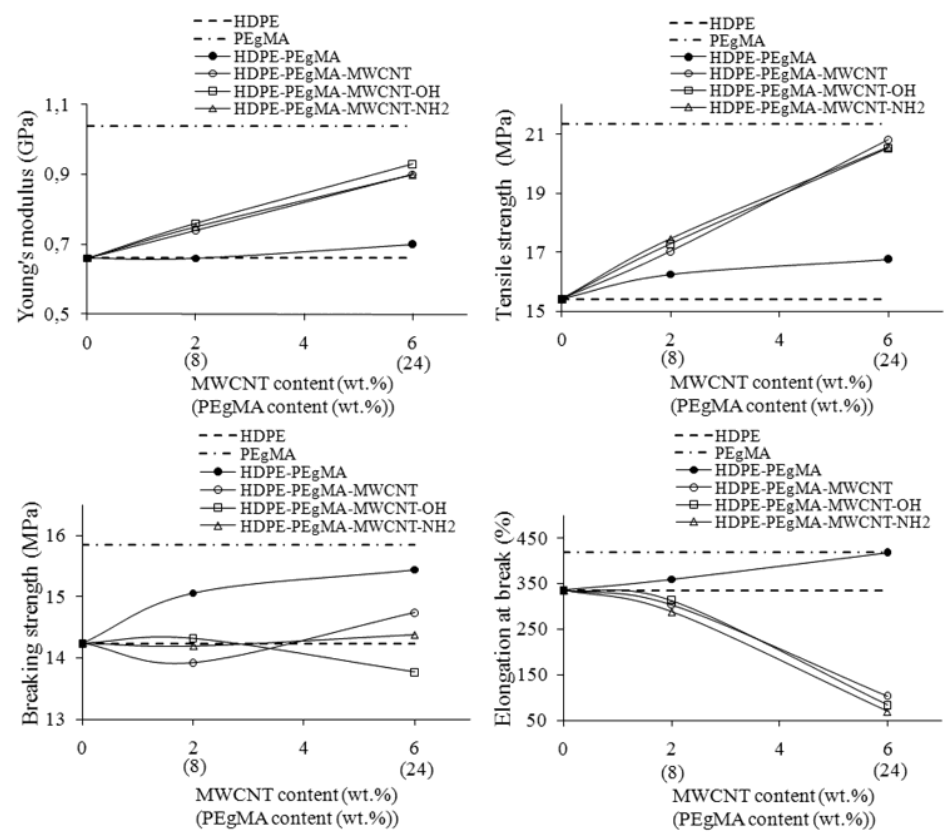

Figure 4. Mechanical properties of HDPE, PEgMA, and HDPE-PEgMA, and of nanocomposites HDPE-PEgMA-MWCNT, HDPE-PEgMA-MWCNT-OH, and HDPEPEgMA-MWCNT-NH 2 . Note that HDPE and PEgMA (dashed lines) and HDPE-PEgMA do not contain CNTs.
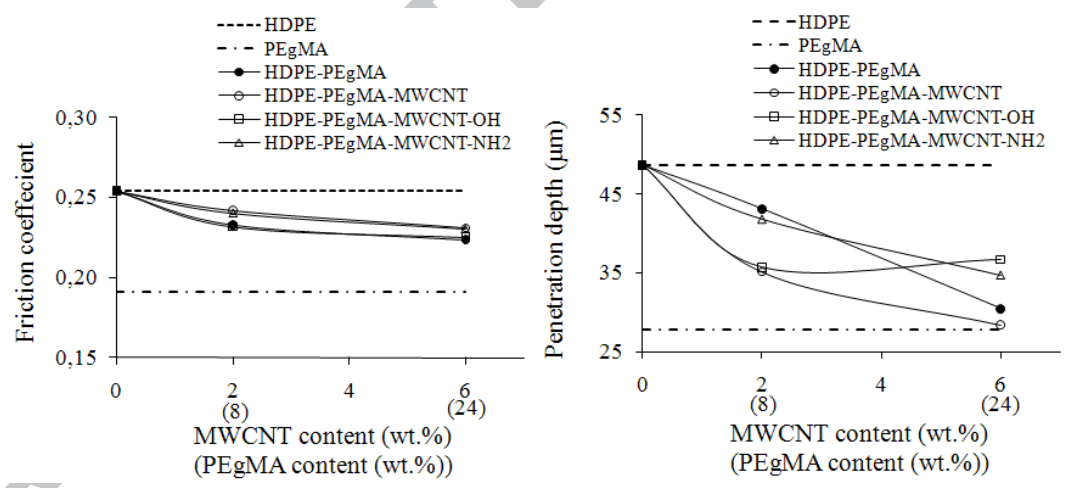

Figure 5. Friction coefficients and wear rates of HDPE-PEgMA-MWCNT, HDPEPEgMA-MWCNT-OH, and HDPE-PEgMA-MWCNT- $\mathrm{NH}_{2}$ nanocomposites against a steel pin compared with those of HDPE, PEgMA and HDPE-PEgMA references. 

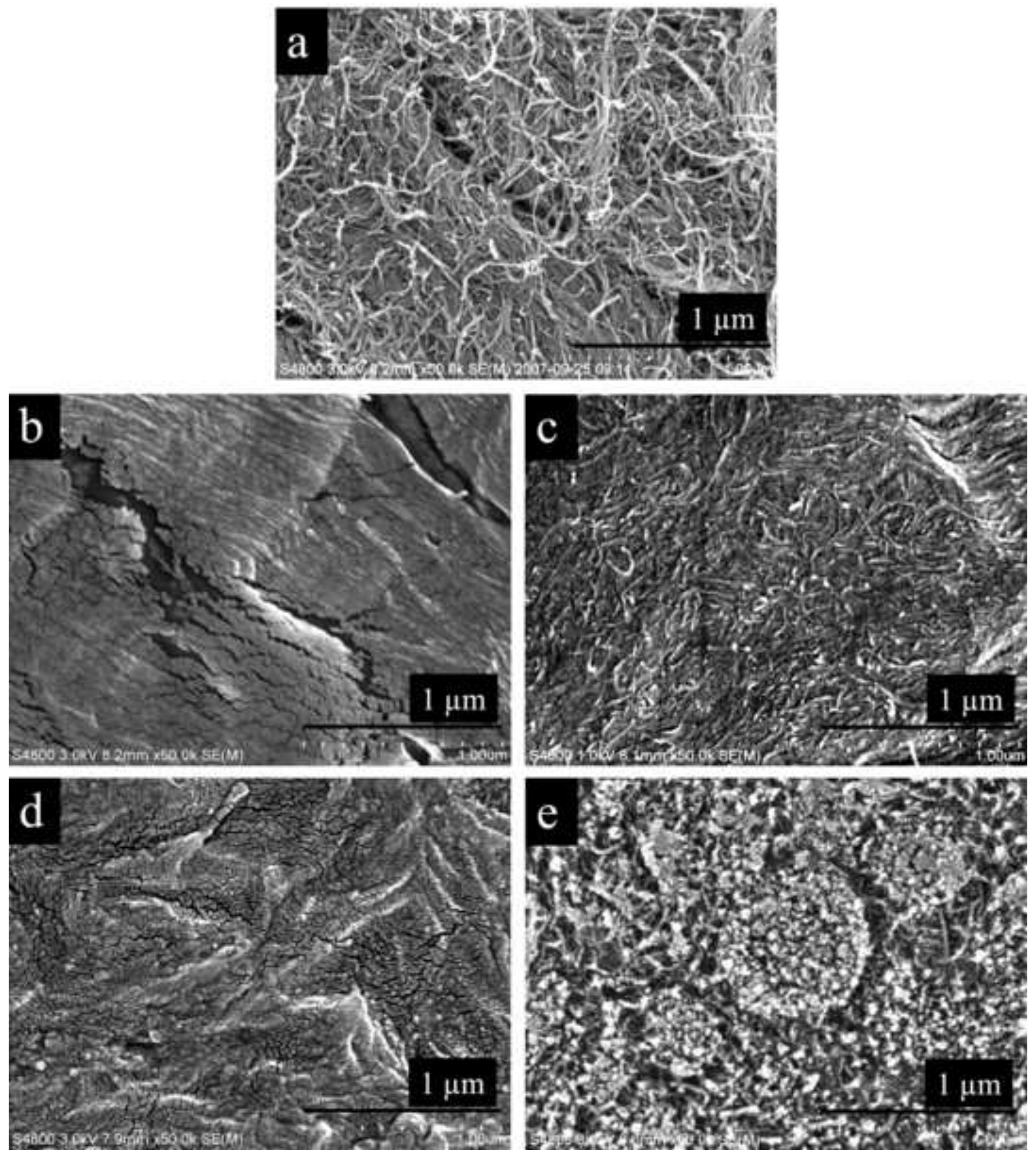

\section{.}

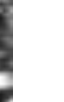

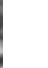




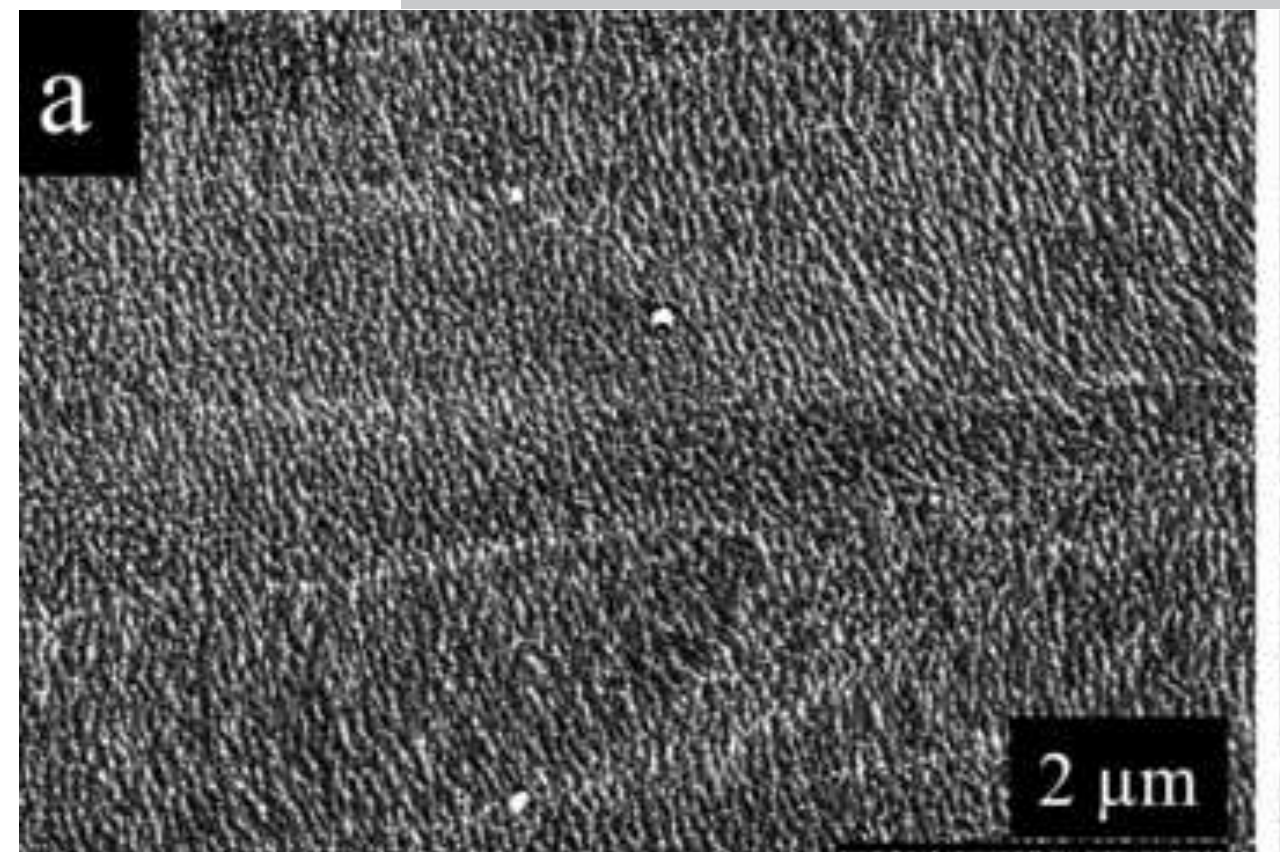

b W

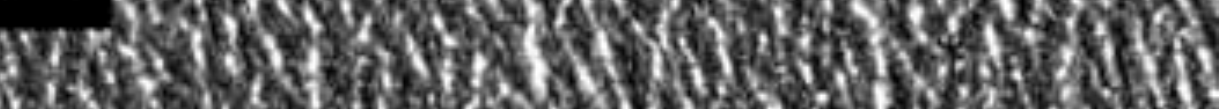
4.

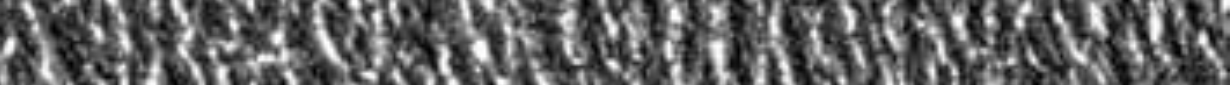

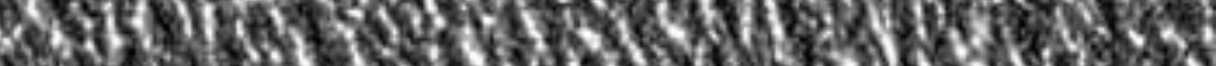

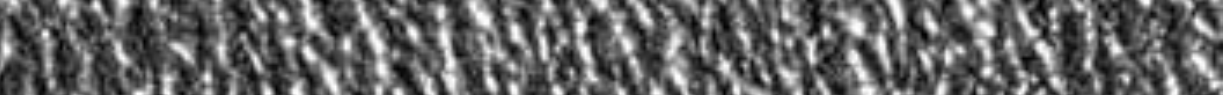

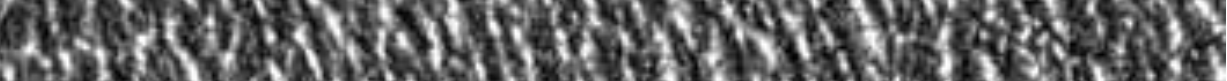

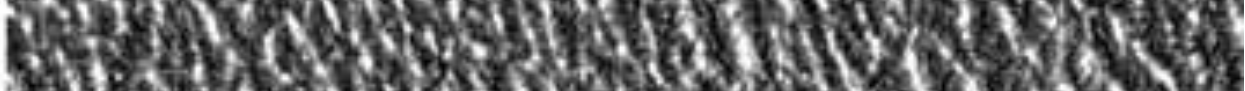
(3)

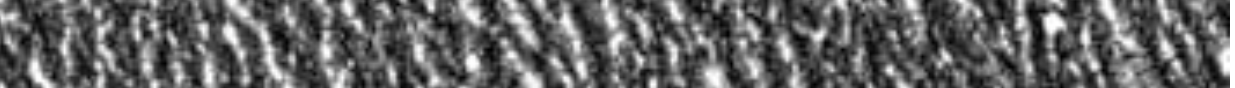
Hor. Hen 7ho (3)

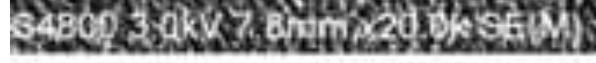
S.
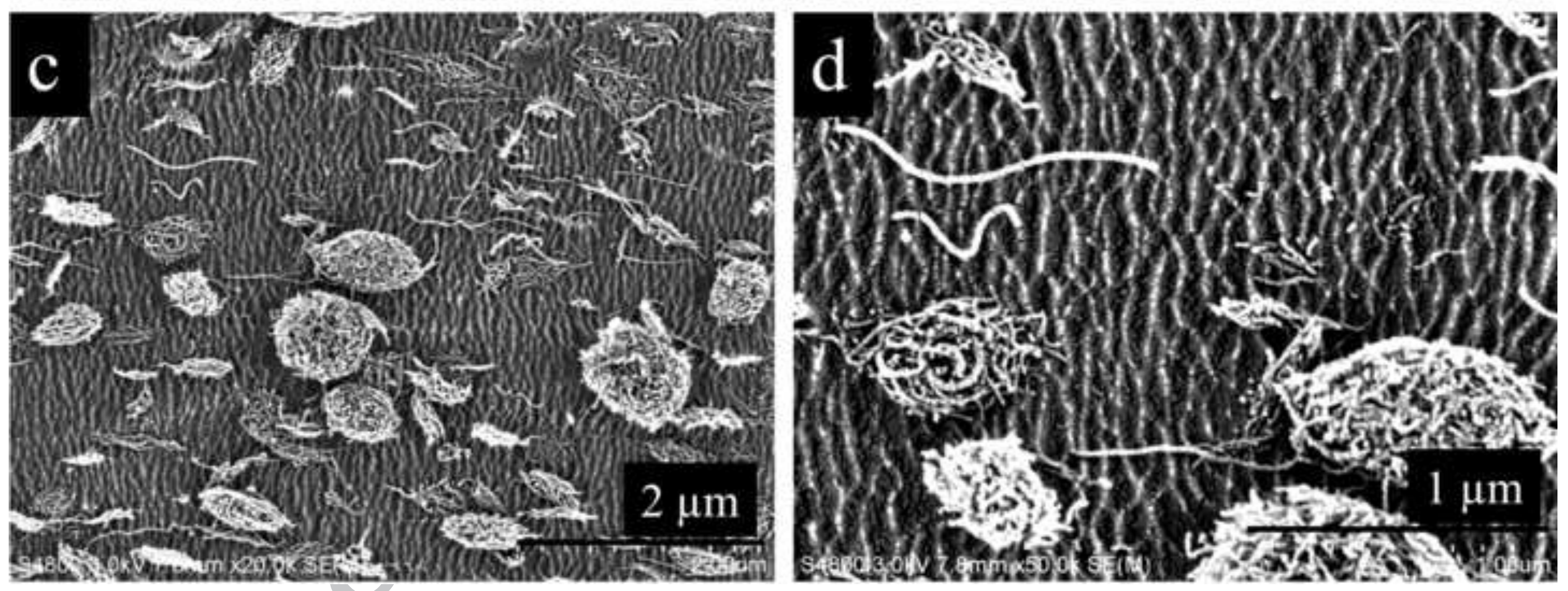

$D$ 

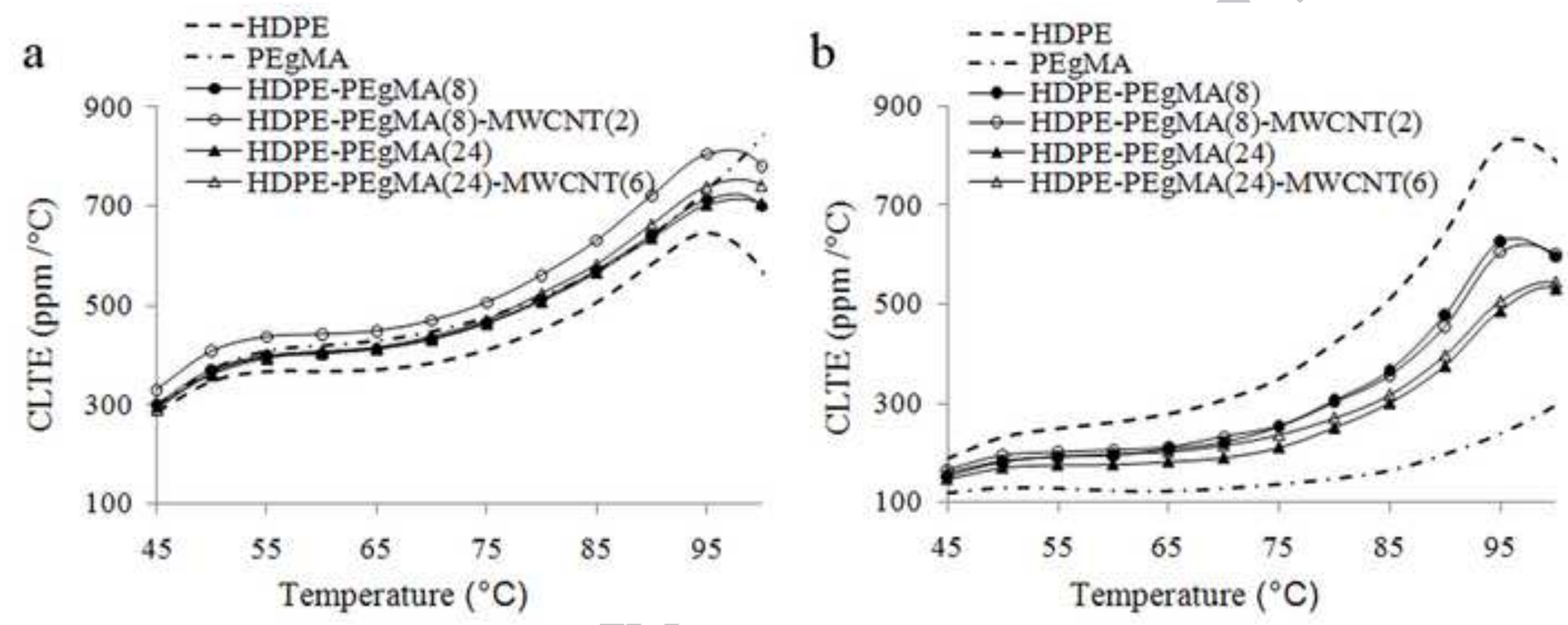


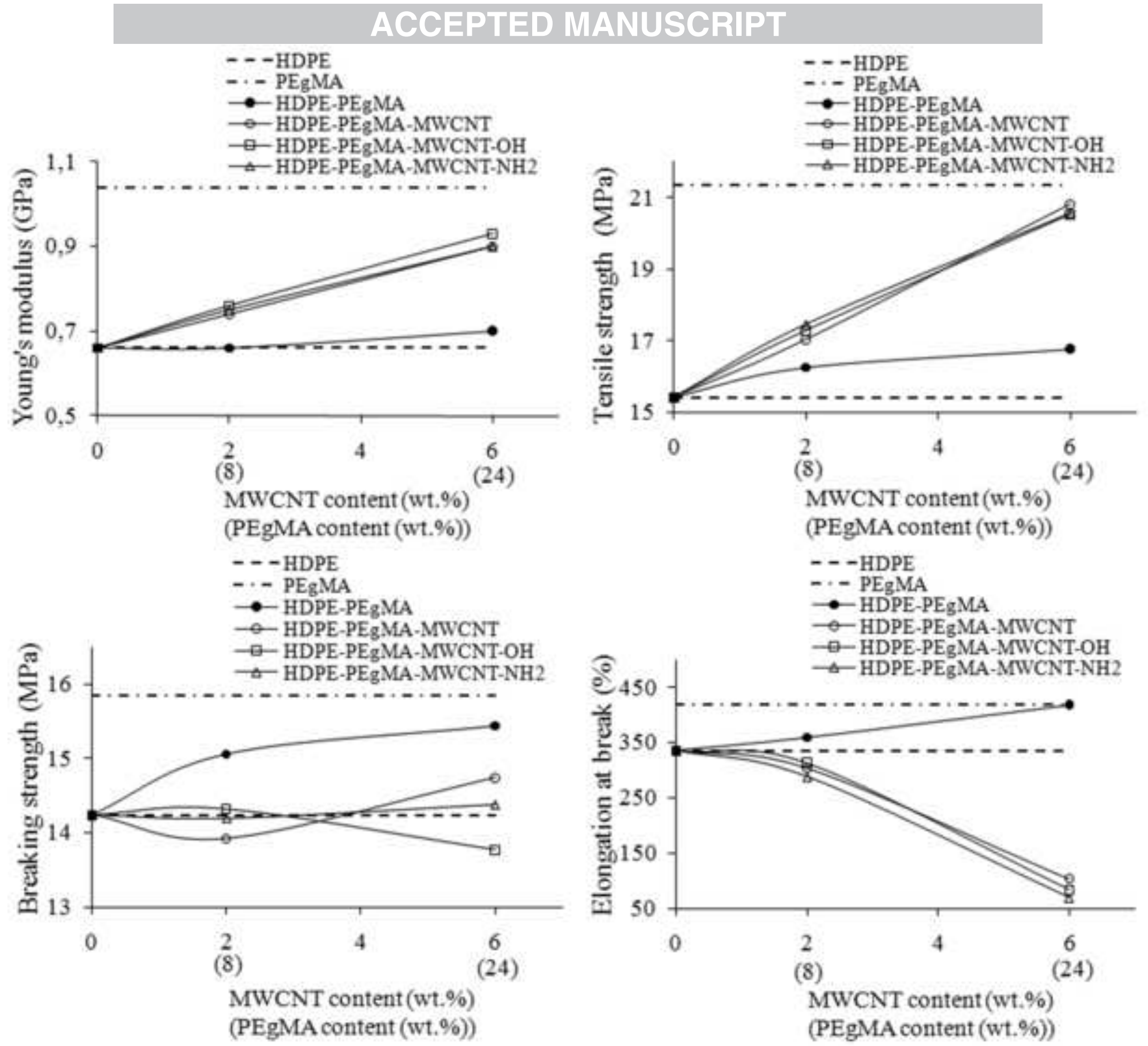

\section{ACCEPTED MANUSCRIPT}

$\mathrm{CNT}$

Q-HDPE-PEgMA-MWCNT-OH

$$
\text { 豆 }
$$

(8)

rWCNT content (wt.\%)

EgMA content (wt.\%))

- HDPE-PEgMA

IDPE-PEgMA-MWCXT-OH

MWCNT content (wt.\%)

(PEgMA content (wt.\%))
- PEgMA

CNT-OH

8)

Ma content (wt.\%)

- -HDPE

- HDPE-PEgMA

- - -

(PEgMA content (wt.\%)) 

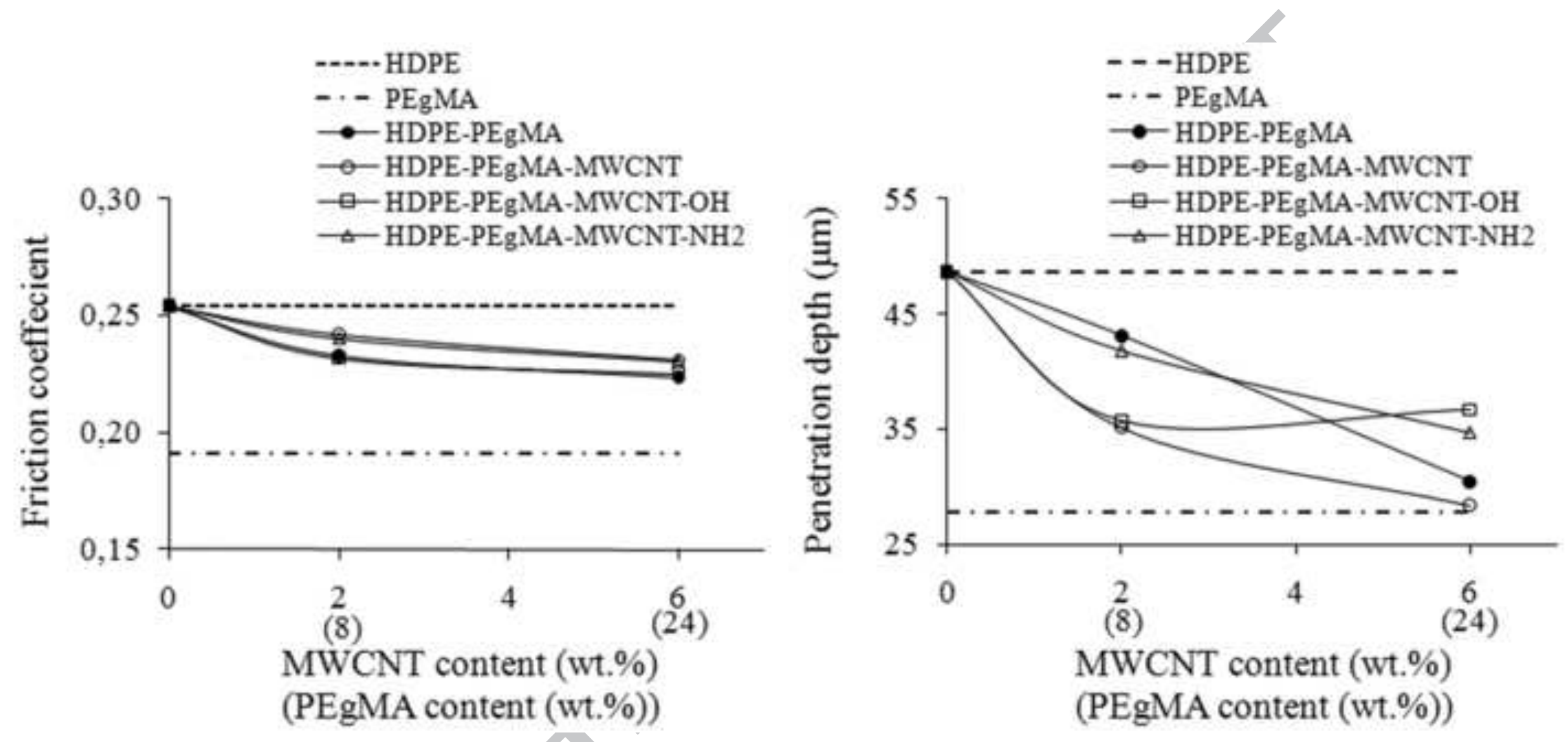